\title{
CASE OF HYSTERO-EPILEPSY.
}

BY W. H. DOBLE, M.B.

Lato Rosident Physician, Edinburgh Royal Infirmary.

THE following case was under the care of Professor Grainger Stewart, to whom I am indebted for permisgion to publish it :T. M., aged 15, a general servant girl, was admitted to the Royal Infirmary, Edinburgh, on June 29th, 1881, suffering from fits of a hysterical character. Her family history was unimportant, save that a cousin was said to have ben subject to epileptic fits in childhood.

The patient, an illegitimate child, was brought up amid poor and not very favourable surroundings. When ten years old, she used often to complain of pain and tenderness in the crown of the head, the least touch causing her to cry out. This subsided gradually under simple medical treatment. Shortly afterwards she became subject to fits, which, from the description given, were apparently epileptic of the petit mal character, recurring at intervals of a week, afterwards less frequently, and liable to be brought on by any unusual excitement. She had no such fit for eighteen months previous to her admission.

In disposition she was cheerful and intelligent; it was remarked, however, that at an early age she showed a propensity for telling lies, not as a rule for her own advantage or any adequate reason-a propensity which has increased with her years. Latterly also she had become possessed by certain delusions which it was almost impossible to dispel, for instance, that her grandmother was dead.

In April, ten weeks before admission, she became general servant in a lodging-house amid unfavourable surroundings. She was much over-worked, and this, together with undue sexual excitement during the same period, would seem to be the immediate cause of her present illness.

On the morning of June 29th the patient left her mistress's house on an errand, apparently in her usual health. She did not return, and afterwards had no recollection of how she 
spent the day; but about eight o'clock in the erening she was found by a policeman at the corner of a street where she had fallen. She appeared to have had a flt, but told her name, and complained loudly of pain in the back. She was accordingly conveyed to the Royal Infirmary a supposed surgical case. After admission she went through a series of hysterical attaoks, such as she has since suffered from at varying intervals.

A typical seizure may be desoribed as follows:-

The patient was perhaps lying comfortably in bod, talking rationally with those about her, when suddenly she complained of a violent pain in the back or side, and putting her hand to the spot, was immediately thrown into a state of tonic spasm, in which the features were fixed, the back arched, the head thrown back, the limbs rigid, the fingers clenched over the thumbs, the eyes staring; and the eye-balls turned up.

From this, which lasted a few seconds, she would pass into a stage of violent contortion, throwing herself from side to side, so that she was with difficulty held down; at one moment arching her back as in tetanus, at the next springing forwards, as if to throw herself out of bed.

The limbs were usually flung about irreguiarly in all directions; but sometimes the arms were repeatedly circumducted, or if possible thrown against some hard object, from which bruises now and then resulted. This violent stage generally lasted from half a minute to a minute, and was succeeded by one of comparative quiet, but was liable to recur at any time during the progress of the fit, being at once set up if any of the sensitive spots, to be afterwards mentioned, were pressed upon. The fit could be checked to some extent by firm pressure over the region of the ovaries, or to a less degree by pressure above the mammø, bat not completely arrested by either.

During the next period she would lie quiet for the most part, no restraint being necessery. Her intellectual faculties became active, although she was unconscious of what was going on around her, or if imperfectly conscious, only associated it with her delusions. Her pulse and respirations were slightly quickened, and there was occasional jerking of the muscles of the face. She was seized with vivid hallucinations, imagining she saw persons and things not really present, and mistaking the identity of those around her, if she could be induced to notice them at all. Usually she made no response to questions, but sometines her hallucinations were influenced by what was said to her.

To give an instance or two :-She, perhaps, fancies herself back in her place as general servant; she is looking after the children of her lite mistress, and culling them by their names; 
if now she be suddenly and londly told it is time to get up she will start up in bed with a confused look, as if afraid she has overslept herself.

Now, perhaps, she sees "Maggie," an old friend, is transported with delight, calls her by name, beckons or whistles to her. The next minute she is crouching beneath the bedclothes, with an expression and attitude of terror at a supposed new presence; and then, as she throws her head back, her features become frightfully distorted, the left side of the face and mouth drawn down, the eye-balls rolled upwards and to one side, the brows knit, while the breathing becomes stertorous, and there is usually more or less recurrence of the stage of contortion.

During the latter part of the emotional stage there were often prolonged fits of yawning, symptoms of choking, stoppage of respiration for long periods, alternating with rapid and forced breathing, or protrusion of the tongue, which, however, was not bitten.

She usually regained consciousness rather suddenly, recognising those around her, complaining of dizziness, sometimes of headache, and either dropping off to sleep, or gradually engaging in conversation. She would become at once perfectly rational, and had then no recollection of her hallucinations, or knowledge that anything out of the way had occurred. Shortly after each seizure she would drink a large quantity of water.

This being the course of the flt itself, the next point of interest is the condition of the nervous system, especially as regards sensory functions.

18t. In the interval between the fits.

2nd. During the fit itself.

1. In the interval between the seizares the patient often complained of pain in the back and right side, of coldness of the feet, dizziness, and headache.

Her sensibility to touch and pain was acnte in all parts of the body, her perception of hot and cold substances good, and her localisation accurate. There were, however, certain areas, varying at different periods, which were over-sensitive. At the time of her admission to hospital this hypermsthesia was best marked over the spinous processes of the lumbar vertebroe and part of the 8acrum, together with an indefinite area to the right of this, notably over bony prominences, the iliac crest and the lowest ribs. In this area hot substances were recognised only as painful, while the slightest pressure, heat, or electrical stimulation, caused her to cry out, and sometimes threw her into a fit. In addition to this, slight ovarian pressure caused pain, and might produce a fit. 
2. When these points were examined into during the prograss of a fit, however, the condition was found to be very different.

Complete anæsthesia was found to exist on both sides of the body; needles might be thrust into the skin without her exhibiting the least expression of sensibility; pricking the forehead, however, caused blinking of the eyelids. The previously hyperæsthetic areas were now for the most part anesthetic; bat firm pressure there would often reproduce the violent stage. The part of the body in which sensation was first regained appeared to be the soles of the feet, the repeated pricking of which sometimes served to dispel the fit; but her first idea of the sensation thus produced was pain referred to the back, or at least to some part of the body not actually pricked. Her power of localisation then was defective during the period of returning consciousness. This was first observed two days after her admission, when a painful abscess in the pulp of the thumb was incised during the quiet stage of the fit, the pain of which caused wincing, but was referred to her back, causing her to sit up and look for a stone in the bed. (She had afterwards no recollection of the abscess being opened.)

The same fact was brought out in a curious manner by pricking repeatedly some portion of the upper extremity in the last stage of the fit. As conscionsness was returning, she complained of the prick of a pin, but indicated the corresponding point on the opposite limb; as consciousness further returns she suddenly indicates the point correctly. [Since these observations were made, it has been pointed out to me by Dr. Hyslop, Royal Edinburgh Asylum, under whose care this patient afterwards came, and who observed the fact independently, that this is an example of the condition described in 'Brain,' July, 1881, as “Allochirio," by Professor Obersteiner, of Vienna.]

With regard to our patient's special senses, nothing was found abnormal in the intervals between the fits, except a considerable degree of myopia. There was no colour-blindness. Ophthalmoscopic examination showed staphyloma posticum, and some atrophy of the choroid. During a fit she had hallucinations of sight as above mentioned, and her sense of hearing was abnormally acute; at on $\theta \operatorname{tim} \theta$, about a week after her admission, she started at the slightest noise, as a footfall in the passage, even when she was quite lucid, and during a fit she would mistake the creaking of the door for a noise under her bed.

The condition of the motor functions during a fit has been describel; at the time of her admission she could support 
herself fairly well on the left leg, but not on the right. On attempting to walk she sank down on her knees, and was often thrown into a fit. This continued for about three weeks, when she gradually regained the power of locomotion, and afterwards showed no sign of muscular enfeeblement.

Tendon reflex was well marked, but not excessive, and the organio reflex functions, with the exception of occasional retention of urine, were normal.

The patient's growth and sexual development were apparently unaffected by her complaint. She continued strong and stout, slept well, and ate heartily as a rule.

Menstruation began six months before admission, and was irregular, the periods frequent, and the flow scanty.

The circulatory and respiratory systems were normal.

The urine was pale straw colour, acid in reaction, of speciflo gravity 1014. The quantity per diem 50 to 60 ounces.

The prodromata of an attack consisted in disinolination to work, drowsiness, dizziness. hesdache, and often pain in the back. The flts, when she was in hospital, usually occurred at night and in the early morning, and she often had one immediately after a period of sleep. When this was the case, she would groan, grind her teoth, and become restless, then waking up, she 'would stare vacantly around her, and immediately pess into the stage of tonic contraction. Occasionally during the daytime she could tell that an attack was coming on, and tried to prevent it by an effort of the will, but without success. As a rule she had no time for this; but she never fell as in a true epileptio fit.

The attacks were more numerous during her menstrual periods, at which time she became especially drowsy and listless.

The duration of an individual fit varied from ton minutes to two hours, and the number per diem from one to six. The series usually continued three or four days, and she was seldom free from them for an entire week.

The patient's peculiar temperament was further shown by a craving for men's society, by fying propensities before referred to, and by other attempts at deception, of which the secret mixing of milk with her urine mas be mentioned as an example; also by the occurrence of periods of melancholy and religious fervour, and by sudden transition from mental depression to exaltation.

Effect of drugs.-1. Chloroform.-On July 9th the patient was put fully under its influence during an attack. After its administration was stopped she attempted to vomit, but appeared to be still in the fit. She presently became conscious, and complained of violent headache.

A smaller quantity of the drug, sufficient to quiet the 
spasms, threw her into a state of mental exaltation, which would continue for an hour or two until she fell asleep.

2. Nitrite of amyl.-On one occasion this drug was inhaled during a fit ; it caused blushing, choking, and apparently some interference with respiration, but did not arrest the fit.

The application of the faradic current gave uncertain results.

Treatment.-Besides freedom from excitement and wholesome discipline, which were secured as far as passible, the following treatment was adopted:-Bromide of potassium gr. xx., with tincture of digitalis $m$ vijss three times a day, together with counter-irritation by repeated fly-blisters, applied over the beck and ovarian regions, and cold shower baths. Valerianate of zino was also tried, but no marked benefit seemed to result from medicinal treatment of any kind.

Progress.-Improvement to some extent took place after she had been a month in hospital; but at the end of three months there was very little change in her condition. When she was sent into the country she again improved for a time, but soon afterwards the fits became as frequent as ever.

Remarks.-Any comment on the above case seems unnecessary. I have ventured to record it as an interesting example, occurring in this country, of a disesso fally described by Charcot, Richer, and othera. 